\begin{tabular}{|c|c|}
\hline Title & Finite Element A nalysis of H-Plane W aveguide Junction with A rbitrarily Shaped Ferrite Post \\
\hline Author(s) & Koshiba, M.; Suzuki, M. \\
\hline Citation & IEEE Transactions on Microwave Theory and Techniques, 34(1), 103-109 \\
\hline Issue Date & $1986-01$ \\
\hline Doc URL & http:/hdl. handle.net/2115/6041 \\
\hline Rights & $\begin{array}{l}\text { O1986 IEEE. Personal use of this material is permitted. However, permission to reprint/republish this material for } \\
\text { advertising or promotional purposes or for creating new collective works for resale or redistribution to servers or lists, } \\
\text { or to reuse any copyrighted component of this work in other works must be obtained from the IEEE." } \\
\text { IEEE, IEEE Transactions on Microwave Theory and Techniques, 34(1), 1986, p103-109 }\end{array}$ \\
\hline Type & article \\
\hline File Information & ITMTT34_1.pdf \\
\hline
\end{tabular}

Instructions for use 


\title{
Finite-Element Analysis of $H$-Plane Waveguide Junction with Arbitrarily Shaped Ferrite Post
}

\author{
MASANORI KOSHIBA, SENIOR MEMBER, IEEE, AND MICHIO SUZUKI, SENIOR MEMBER, IEEE
}

\begin{abstract}
A numerical approach for solving the problem of $\boldsymbol{H}$-plane waveguide junctions with lossy ferrite posts of arbitrary shape is proposed. The junctions are allowed to have arbitrary cross section. The approach is a combination of the finite-element method and the analytical method. To show the validity and usefulness of the method, $\mathrm{Y}$-junction circulators with a circular ferrite post are considered. Our results agree well with earlier experimental and theoretical results. The performances of $\mathrm{Y}$-junction circulators with a triangular equilateral ferrite post or a triangular ferrite post having depressed sides are investigated. The influences of the ferrite losses on the performance are examined.
\end{abstract}

\section{INTRODUCTION}

A PPLICATIONS OF waveguide junctions with ferrite posts have been of wide-ranging use in microwave devices and circuits, and research on them has been continued steadily. Davies [1] presented the theoretical treatment for a symmetrical waveguide junction circulator with a circular ferrite post. This method was extended to junctions with coaxial composite ferrite posts which produced much larger bandwidths [2]-[4]. This analysis, however, is limited for junctions that have geometrical symmetry. Recently, the point-matching method was extended to the asymmetrical junctions [5] and was applied to the junctions with a triangular ferrite post [6]. The point-matching technique is powerful for the waveguide junctions with arbitrarily shaped ferrite posts, but the ferrite losses are neglected. Okamoto [7] presented a method based on the integral equations for solving the problem of waveguide junctions with lossy ferrite posts. In his approach, the junctions are allowed to have an arbitrary cross section and arbitrary number of ports, but only the ferrite posts with smooth boundaries such as a circular ferrite post and a triangular ferrite post having rounded angles are studied.

In this paper, a finite-element method for the analysis of the $H$-plane waveguide junctions with lossy ferrite posts of arbitrary shape is described.

For the analysis of planar circulators, Lyon and Helszajn [8] presented a method based on circuit theory and the finite-element method. In their approach, the system is assumed to be free of any losses and the finite-element method is used for the computation of the eigenvalues and eigenvectors of the normal modes of a magnetized ferrite

\footnotetext{
Manuscript received April 2, 1985; revised July 26, 1985.

The authors are with the Department of Electronic Engineering, Hokkaido University, Sapporo, 060 Japan.

IEEE Log Number 8405813.
}

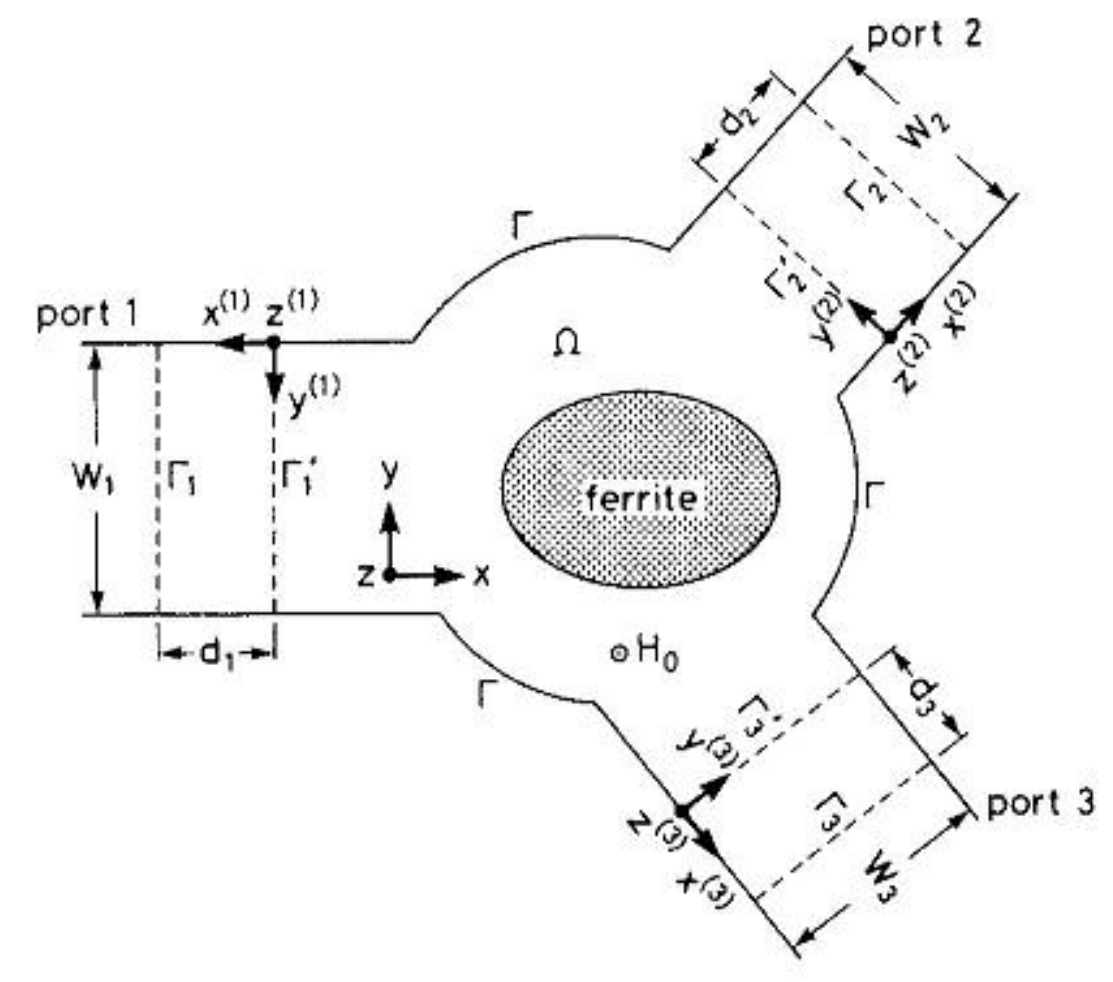

Fig. 1. Geometry of problem.

resonator, and then the circuit parameters are determined by using these data of the normal modes. Their approach is very useful for the planar circulators using arbitrarily shaped resonators and it can be applied to $H$-plane waveguide junctions with arbitrarily shaped ferrite posts. However, the scattering coefficients are quite sensitive to the values of the circuit parameters, so it is necessary to ensure that sufficient significant digits are carried through in the computation of the normal modes. In our approach, on the other hand, it is not necessary to compute the eigenvalues and eigenvectors of the normal modes. Making use of the method, we first treat $\mathrm{Y}$-junction circulators with a circular ferrite post for comparison with the previously published experimental and theoretical results [3], [5]--[7]. The performance of $\mathrm{Y}$-junction circulators with a triangular equilateral ferrite post or a triangular ferrite post having depressed sides are next investigated. The influences of the ferrite losses on the performance are examined.

\section{BASIC EQUATIONS}

Fig. 1 shows the $H$-plane waveguide junction with a full-height ferrite post of arbitrary shape. The dc magnetic field is applied in parallel with the $z$ axis. The boundaries $\Gamma_{i^{\prime}}\left(i^{\prime}=1^{\prime}, 2^{\prime}, 3^{\prime}\right)$ lie in the region $\Omega$ with $\Gamma_{i}(i=1,2,3)$ and the short-circuit boundary $\Gamma$, and the region surrounded by $\Gamma_{i}$, and $\Gamma$ completely encloses the waveguide discontinuities. In general, the waveguides need not be symmetrically 
located around the junction. Although the number of ports is arbitrary, for simplicity, three-port junctions are considered. The waveguides propagate only the dominant $\mathrm{TE}_{10}$ mode, while all higher modes are cutoff. However, this does not mean that the higher modes are neglected.

With a time dependence of the form $\exp (j \omega t)$ being implied, the permeability tensor $[\mu]$ is [9]

$$
[\mu]=\left[\begin{array}{ccc}
\mu & -j \kappa & 0 \\
j \kappa & \mu & 0 \\
0 & 0 & \mu_{0}
\end{array}\right]
$$

where

$$
\begin{aligned}
\mu & =\mu_{0}\left\{1+\frac{\left(\omega_{0}+j \omega \alpha\right) \omega_{m}}{\left(\omega_{0}+j \omega \alpha\right)^{2}-\omega^{2}}\right\} \\
\kappa & =-\mu_{0} \frac{\omega \omega_{m}}{\left(\omega_{0}+j \omega \alpha\right)^{2}-\omega^{2}} \\
\omega_{0} & =\gamma H_{0} \\
\omega_{m} & =\gamma M_{s} / \mu_{0} \\
\alpha & =\gamma \Delta H / 2 \omega .
\end{aligned}
$$

Here $\omega$ is the angular frequency, $\mu_{0}$ is the permeability of free space, $H_{0}$ is the internal dc magnetic field, $M_{s}$ is the saturation magnetization, $\Delta H$ is the resonance linewidth, $\gamma$ is the gyromagnetic ratio, and $[\cdot]$ denotes a matrix.

Considering the excitation by the dominant $\mathrm{TE}_{10}$ mode, the field $E_{z}, H_{x}$, and $H_{y}$ satisfy the following relations:

$$
\begin{aligned}
\frac{\partial H_{y}}{\partial x}-\frac{\partial H_{x}}{\partial y} & =j \omega \epsilon E_{z} \\
H_{x} & =\frac{1}{j \omega\left(\mu^{2}-\kappa^{2}\right)}\left\{-\mu \frac{\partial E_{z}}{\partial y}+j \kappa \frac{\partial E_{z}}{\partial x}\right\} \\
H_{y} & =\frac{1}{j \omega\left(\mu^{2}-\kappa^{2}\right)}\left\{\mu \frac{\partial E_{z}}{\partial x}+j \kappa \frac{\partial E_{z}}{\partial y}\right\}
\end{aligned}
$$

where

$$
\epsilon=\epsilon_{0} \epsilon_{s}(1-j \tan \delta) .
$$

Here $\epsilon_{0}$ is the permittivity of free space, $\epsilon_{s}$ is the relative permittivity, and $\delta$ is the dielectric loss angle.

\section{Mathematical Formulation}

\section{A. Finite-Element Approach}

Dividing the region $\Omega$ into a number of second-order triangular elements in Fig. 2, the electric field $E_{z}$ within each element is defined in terms of the electric field $E_{z}$ at the corner and midside nodal points

$$
E_{z}=\{N\}^{T}\left\{E_{z}\right\}_{e}
$$

where $\left\{E_{z}\right\}_{e}$ is the electric field vector corresponding to the nodal points within each element, $\{N\}$ is the shape function vector [10], and $T,\{\cdot\}$, and $\{\cdot\}^{T}$ denote a transpose, a column vector, and a row vector, respectively.

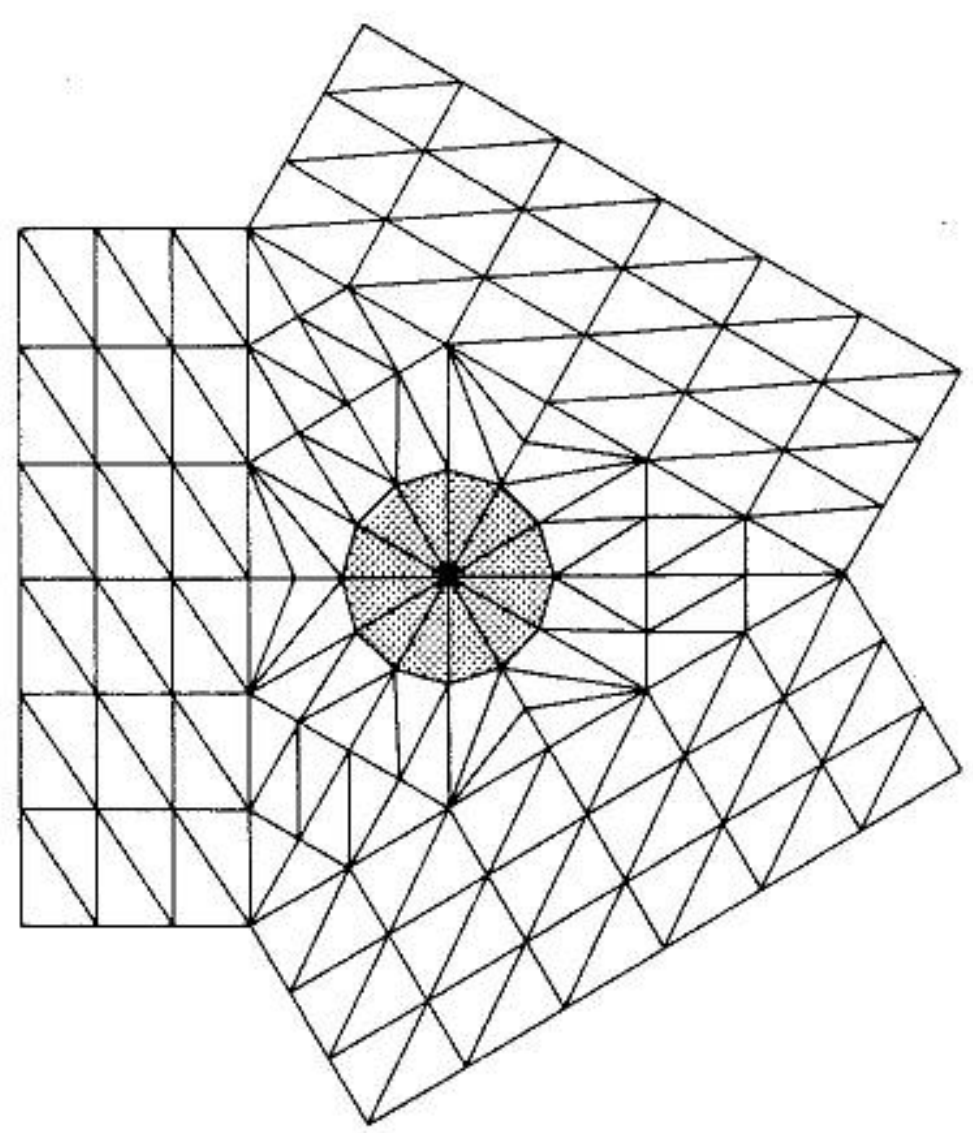

(a)

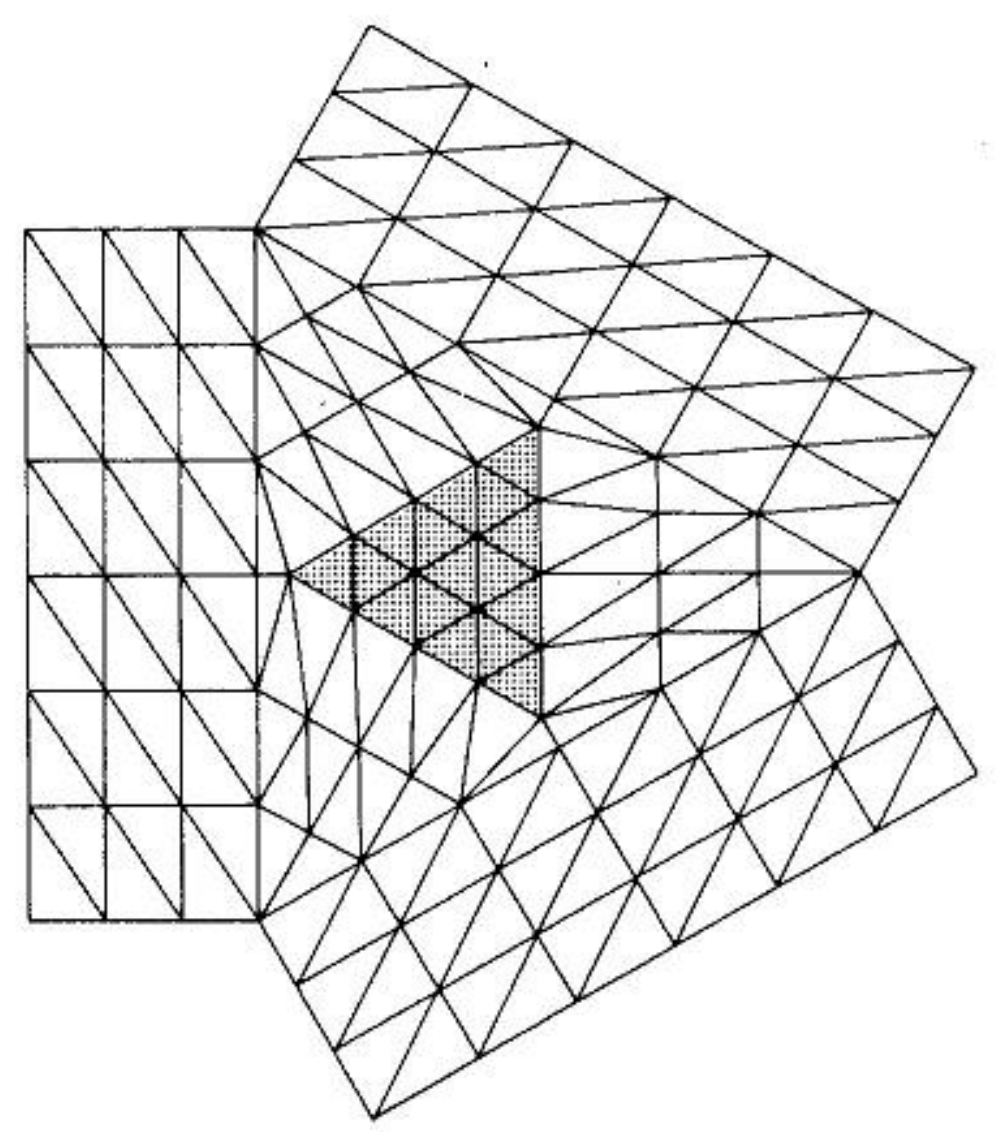

(b)

Fig. 2. Typical divisions for $H$-plane waveguide junctions with a ferrite post. (a) Circular ferrite post. (b) Triangular ferrite post.

Using a Galerkin procedure on (7), we obtain

$$
\iint_{e}\{N\}\left(\frac{\partial H_{y}}{\partial x}-\frac{\partial H_{x}}{\partial y}-j \omega \epsilon E_{z}\right) d \Omega=\{0\}
$$

where the integration is carried over the element subdomain $\Omega_{e}$ and $\{0\}$ is a null vector.

Integrating by parts, (12) becomes

$$
\begin{aligned}
\iint_{e}\left(\frac{\partial\{N\}}{\partial x} H_{y}-\frac{\partial\{N\}}{\partial y} H_{x}\right. & \left.+j \omega \epsilon E_{z}\right) d \Omega \\
& -\int_{e}\{N\} H_{t} d \Gamma=\{0\}
\end{aligned}
$$

where the second integration on the left-hand side is car ried over the contour $\Gamma_{e}$ of the region $\Omega_{e}$, and $H_{t}$ is the transverse component of the magnetic field on $\Gamma_{e}$.

Substituting (8) and (9) into (13), considering $\mu=\mu_{0}$ and $\kappa=0$ on $\Gamma_{i}$, and $E_{z}=0$ on $\Gamma$, using (11), and assembling 
the complete matrix for the region $\Omega$ by adding the contributions of all different elements, we obtain

$$
\begin{aligned}
& {[A]\left\{E_{z}\right\}-\left.\sum_{i=1}^{3} \sum_{e} \int_{e}\{N\} \frac{\partial E_{z}}{\partial x^{(i)}}\right|_{\Gamma_{i}} d y^{(i)}=\{0\} } \\
& {[A]=} \sum_{e} \iint\left[\frac { \mu _ { 0 } } { \mu ^ { 2 } - \kappa ^ { 2 } } \left\{\mu \left(\frac{\partial\{N\}}{\partial x} \frac{\partial\{N\}^{T}}{\partial x}\right.\right.\right. \\
&\left.+\frac{\partial\{N\}}{\partial y} \frac{\partial\{N\}^{T}}{\partial y}\right) \\
&\left.+j \kappa\left(\frac{\partial\{N\}}{\partial x} \frac{\partial\{N\}^{T}}{\partial y}-\frac{\partial\{N\}}{\partial y} \frac{\partial\{N\}^{T}}{\partial x}\right)\right\} \\
&\left.-\epsilon_{s}(1-j \tan \delta) k_{0}^{2}\{N\}\{N\}^{T}\right] d x d y
\end{aligned}
$$

where

$$
k_{0}^{2}=\omega^{2} \epsilon_{0} \mu_{0} .
$$

Here the components of the $\left\{E_{z}\right\}$ vector are the values of the only nonzero components of the electric field $E_{z}$ at all nodal points in the region $\Omega$ except the short-circuit boundary $\Gamma, \Sigma_{e}$ and $\sum_{e}^{\prime}$ extend over all different elements and the elements related to $\Gamma_{i}$, respectively, and $[A]$ is a complex matrix. For loss-free materials, namely $\Delta H=0$ and $\tan \delta=0,[A]$ becomes Hermitian. For $H$-plane waveguide junctions without ferrite posts, namely $\mu=\mu_{0}$ and $\kappa=0$, (14) is reduced to the equation derived by Koshiba, Sato, and Suzuki [11], [12].

We may rewrite (14) as follows:

$$
\begin{aligned}
{\left[\begin{array}{ccc}
{[A]_{\mathrm{II}}} & {[A]_{\mathrm{I} B^{\prime}}} & {[A]_{\mathrm{I} B}} \\
{[A]_{B^{\prime} \mathrm{I}}} & {[A]_{B^{\prime} B^{\prime}}} & {[A]_{B^{\prime} B}} \\
{[A]_{B \mathrm{I}}} & {[A]_{B B^{\prime}}} & {[A]_{B B}}
\end{array}\right]\left[\begin{array}{c}
\left\{E_{z}\right\}_{\mathrm{I}} \\
\left\{E_{z}\right\}_{B^{\prime}} \\
\left\{E_{z}\right\}_{B}
\end{array}\right] } \\
=\left[\begin{array}{c}
\{0\} \\
\{0\} \\
\left.\sum_{e}^{\prime} \int_{e}\{N\} \frac{\partial E_{z}}{\partial x^{(i)}}\right|_{\Gamma_{i}} d y^{(i)}
\end{array}\right]
\end{aligned}
$$

where

$$
\begin{aligned}
\left\{E_{z}\right\}_{B} & =\left[\begin{array}{l}
\left\{E_{z}\right\}_{1} \\
\left\{E_{z}\right\}_{2} \\
\left\{E_{z}\right\}_{3}
\end{array}\right] \\
\left\{E_{z}\right\}_{B^{\prime}} & =\left[\begin{array}{l}
\left\{E_{z}\right\}_{1^{\prime}} \\
\left\{E_{z}\right\}_{2^{\prime}} \\
\left\{E_{z}\right\}_{3^{\prime}}
\end{array}\right] .
\end{aligned}
$$

Here the components of the $\left\{E_{z}\right\}_{i}$ and $\left\{E_{z}\right\}_{i^{\prime}}$ vectors are the values of the electric field $E_{z}$ at nodal points on the boundaries $\Gamma_{i}(i=1,2,3)$ and $\Gamma_{i^{\prime}}\left(i^{\prime}=1^{\prime}, 2^{\prime}, 3^{\prime}\right)$, respectively, the components of the $\left\{E_{z}\right\}_{\mathrm{I}}$ vector are the values of $E_{z}$ at nodal points in the interior region except the boundaries $\Gamma$, $\Gamma_{i}$, and $\Gamma_{i}$, and $[A]_{\mathrm{II}},[A]_{\mathrm{I} B}, \cdots$, and $[A]_{B B}$ are the submatrices of $[A]$.

\section{B. Analytical Approach}

Assuming that the dominant $\mathrm{TE}_{10}$ mode of unit amplitude is incident from the waveguide $j(j=1,2,3)$ in Fig. 1, $E_{z}$ on $\Gamma_{i}$ may be expressed analytically as

$$
\begin{aligned}
E_{z}\left(x^{(i)}=d_{i}, y^{(i)}\right)= & \delta_{i j} 2 j\left(\sin \beta_{j 1} d_{j}\right) f_{j 1}\left(y^{(j)}\right) \\
+ & \sum_{m=1}^{\infty} \int_{0}^{w_{i}} \exp \left(-j \beta_{i m} d_{i}\right) \\
& \cdot f_{i m}\left(y^{(i)}\right) f_{i m}\left(y_{0}^{(i)}\right) \\
& \cdot E_{z}\left(x^{(i)}=0, y_{0}^{(i)}\right) d y_{0}^{(i)}
\end{aligned}
$$

where

$$
\begin{aligned}
f_{i m}\left(y^{(i)}\right) & =\sqrt{2 / W_{i}} \sin \left(m \pi / W_{i}\right) y^{(i)} \\
\beta_{i m} & =\sqrt{k_{0}^{2}-\left(m \pi / W_{i}\right)^{2}} .
\end{aligned}
$$

Here $\delta_{i j}$ is the Kronecker $\delta$.

Using (11), (19) can be discretized as follows:

$$
\left\{E_{z}\right\}_{i}=\delta_{i j}\{f\}_{j}+[Z]_{i}\left\{E_{z}\right\}_{i^{\prime}}
$$

where

$$
\begin{aligned}
&\{f\}_{j}=2 j \sin \beta_{j 1} d_{j}\left\{f_{1}\right\}_{j} \\
& {[Z]_{i}=\sum_{m=1}^{\infty} \exp \left(-j \beta_{i m} d_{i}\right)\left\{f_{m}\right\}_{i} \sum_{e^{\prime}} \int_{e^{\prime}} f_{i m}\left(y_{0}^{(i)}\right) } \\
& \cdot\left\{N\left(x^{(i)}=0, y_{0}^{(i)}\right)\right\} d y_{0}^{(i)} .
\end{aligned}
$$

Here the components of the $\left\{f_{m}\right\}_{i}$ vector are the values of $f_{i m}\left(y^{(i)}\right)$ at the nodal points on $\Gamma_{i}$ and $\Sigma_{e^{\prime}}^{\prime}$ extends over the elements related to $\Gamma_{i}$,

\section{Combination of Finite-Element and Analytical Relations}

Using (22), from (16) we obtain the following final matrix equation:

$$
\left[\begin{array}{ccc}
{[A]_{\mathrm{II}}} & {[A]_{B^{\prime}}} & {[A]_{1 B}} \\
{[A]_{B^{\prime}}} & {[A]_{B^{\prime} B^{\prime}}} & {[A]_{B^{\prime} B}} \\
\hdashline[0] & -[\bar{Z}] & {[1]}
\end{array}\right]\left[\begin{array}{c}
\left\{E_{z}\right\}_{\mathrm{I}} \\
\left\{E_{z}\right\}_{B^{\prime}} \\
\left\{E_{z}\right\}_{B}
\end{array}\right]=\left[\begin{array}{c}
\{0\} \\
\{0\} \\
\{\{f\}
\end{array}\right]
$$

where

$$
\begin{aligned}
& {[Z]=\left[\begin{array}{ccc}
{[Z]_{1}} & {[0]} & {[0]} \\
{[0]} & {[Z]_{2}} & {[0]} \\
{[0]} & {[0]} & {[Z]_{3}}
\end{array}\right]} \\
& \{f\}=\left[\begin{array}{l}
\delta_{1 j}\{f\}_{j} \\
\delta_{2 j}\{f\}_{j} \\
\delta_{3 j}\{f\}_{j}
\end{array}\right]
\end{aligned}
$$

Here [1] is a unit matrix and [0] is a null matrix.

The values of $E_{z}$ at nodal points on $\Gamma_{i}$, namely $\left\{E_{z}\right\}_{i^{\prime}}$, are computed from (25), and then the electric field $E_{z}\left(x^{(i)}\right.$ $\left.=0, y^{(i)}\right)$ on $\Gamma_{i^{\prime}}$ can be calculated from (11). The solutions on $\Gamma_{i}$, allow the determination of the power reflection coefficient $\left|R_{j j}\right|^{2}$ and the power transmission coefficient 


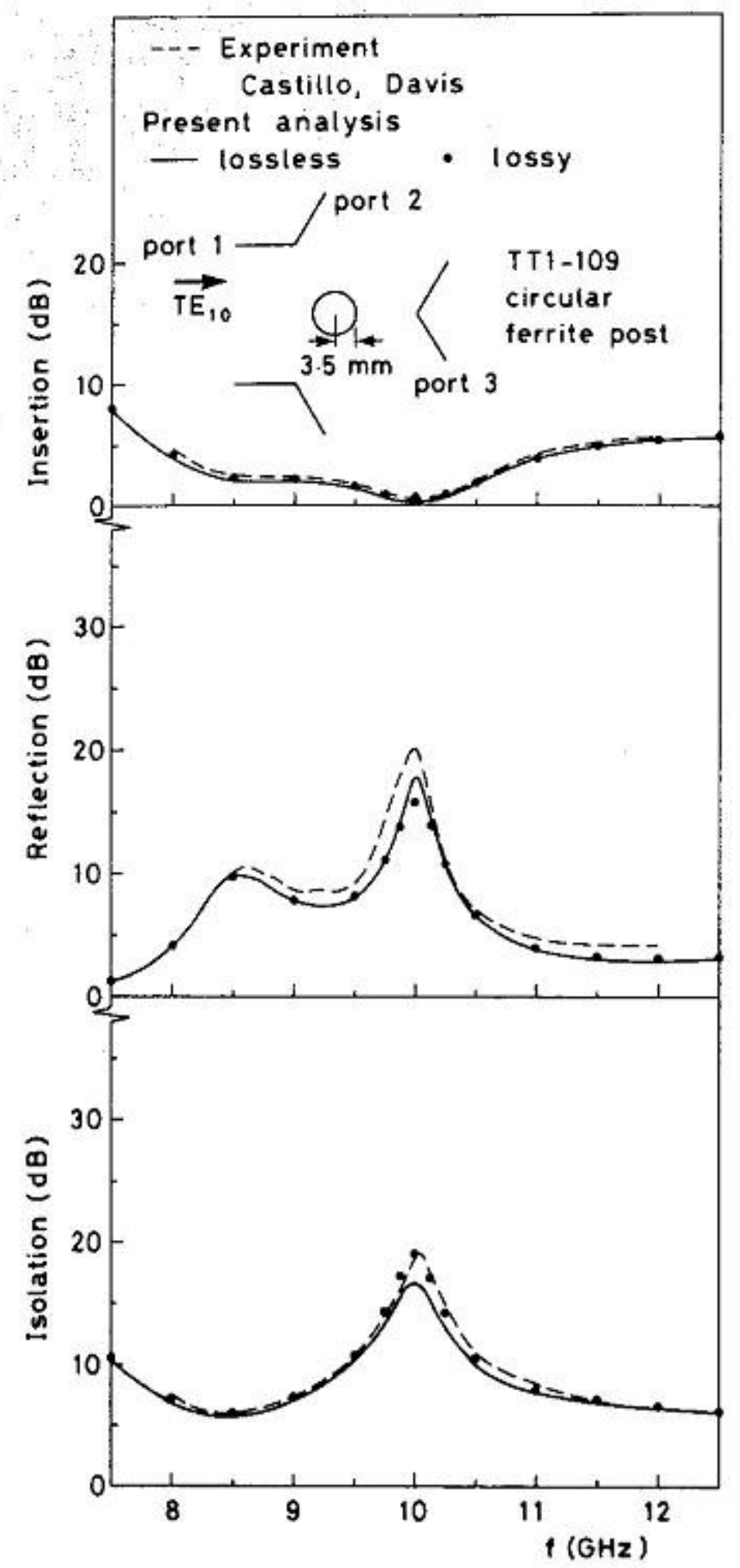

Fig. 3. Performance of a Y-junction with a TT1-109 circular ferrite post.

$\left|T_{i j}\right|^{2}$ as follows:

$$
\begin{array}{r}
\left|R_{j j}\right|^{2}=\left|\int_{0}^{W_{j}} E_{z}\left(x^{(j)}=0, y^{(j)}\right) f_{j 1}\left(y^{(j)}\right) d y^{(j)}-1\right|^{2} \\
\left|T_{i j}\right|^{2}=\frac{\beta_{i 1}}{\beta_{j 1}}\left|\int_{0}^{W_{i}} E_{z}\left(x^{(i)}=0, y^{(i)}\right) f_{i 1}\left(y^{(i)}\right) d y^{(i)}\right|^{2}, \\
i \neq j .
\end{array}
$$

\section{Numerical Results}

We consider a Y-junction circulator with a central ferrite post. A typical division of this circulator into second-order triangular elements is shown in Fig. 2, where the widths of three waveguides are the same and $W_{1}=W_{2}=W_{3}=22.86$ $\mathrm{mm}$. Convergence of the solutions is checked by increasing $m$ in (24) and the number of the elements. Although the convergence is obtained in the case of $m=4$ or 5 , in this analysis, the first six evanescent higher modes are used in (24), namely $m=7$. Assuming that the $\mathrm{TE}_{10}$ mode is incident from the port 1 , the reflection, isolation, and insertion losses [1]-[7] are calculated as follows:

$$
\begin{aligned}
& \text { Reflection Loss }=-20 \log _{10}\left|R_{11}\right|(\mathrm{dB}) \\
& \text { Isolation Loss }=-20 \log _{10}\left|T_{21}\right|(\mathrm{dB}) \\
& \text { Insertion Loss }=-20 \log _{10}\left|T_{31}\right|(\mathrm{dB}) .
\end{aligned}
$$

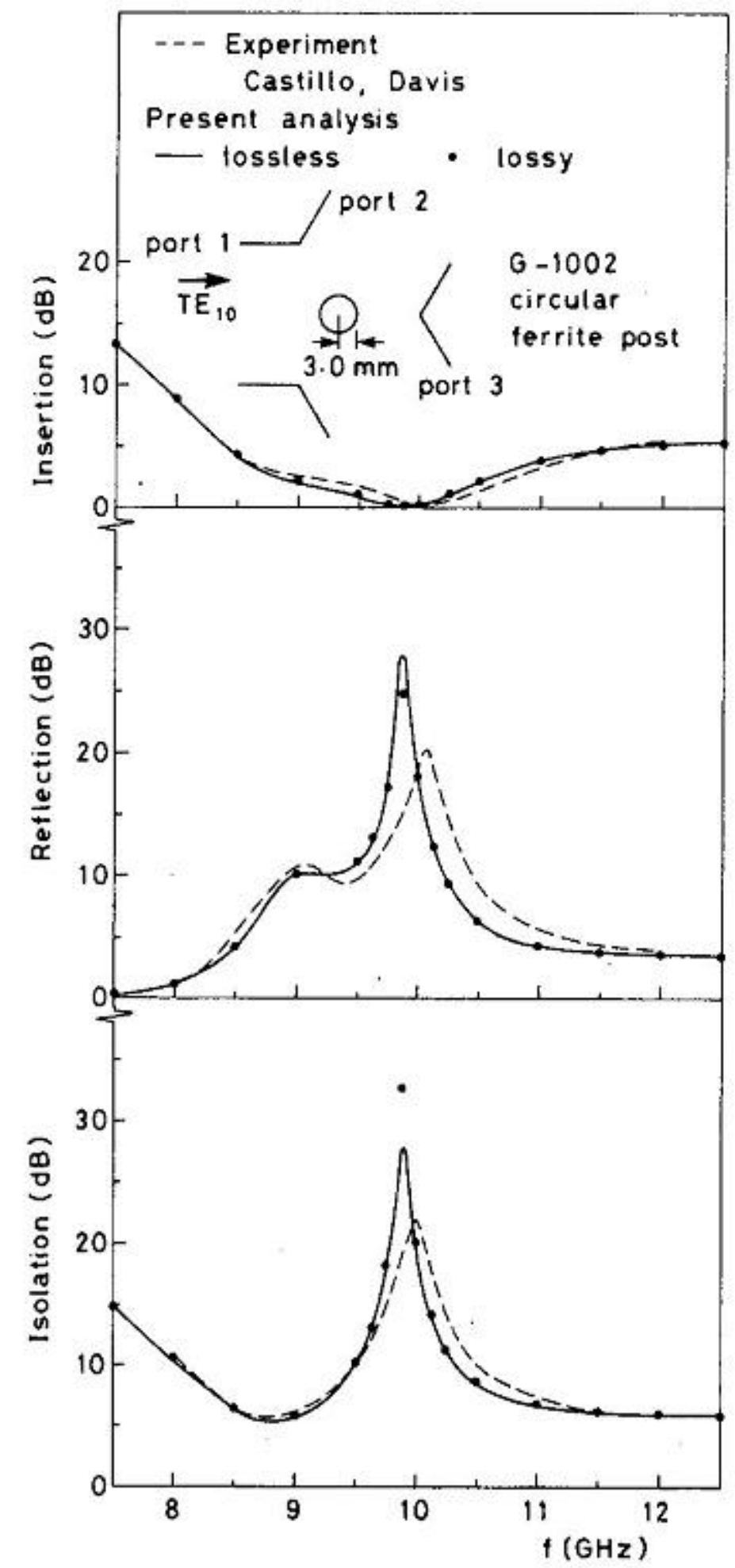

Fig. 4. Performance of a $Y$-junction with a G-1002 circular ferrite post

The dissipative loss $P_{d}$ is given by

$$
P_{d}=1-\left(\left|R_{11}\right|^{2}+\left|T_{21}\right|^{2}+\left|T_{31}\right|^{2}\right) \text {. }
$$

\section{A. Y-Junction with a Central Circular Ferrite Post}

For comparison with previously published experimental and theoretical results, we first treat $\mathrm{Y}$-junction circulators with a central circular ferrite post. There is some difference between the earlier theoretical results [3], [5]-[7].

The circulator performances using two different ferrite samples, that is, TT1-109 and G-1002, have been calcu lated and are shown in Figs. 3 and 4, respectively, where only the magnetic losses are considered and the dielectric losses are neglected, namely $\Delta H \neq 0$ and $\tan \delta=0$. Material parameters are given in [3], [5]-[7]. The results for $\Delta H=0$ (lossless) are represented by the solid lines, while the results for $\Delta H \neq 0$ (lossy) are represented by the dots. The experimental results of Castillo and Davis [3] are also represented by the dashed lines. In lossless cases, the condition of power conservation $\left|R_{11}\right|^{2}+\left|T_{21}\right|^{2}+\left|T_{31}\right|^{2}=1$ is satisfied to an accuracy of $\pm 10^{-4}$. In the lossy cases, the isolation slightly meliorates and the reflection slightly de. teriorates in the neighborhood of the respective maxima of the performance curves in comparison with the lossless cases [7]. For the lossy case in Fig. 3, the numerical resulto (dots) agree approximately with the experimental results 
TABLE I

DisSIPATIVE LosSES OF Y-JUNCTIONS WITH a Circular Ferrite Post

\begin{tabular}{c|c|c|c|c}
\hline \multirow{2}{*}{$\begin{array}{c}\text { Frequency } \\
(\mathrm{GHz})\end{array}$} & \multicolumn{3}{|c|}{ TTi-109 } & G-1002 \\
\cline { 2 - 5 } & $=0$ & $\begin{array}{c}\tan \delta \\
=0.0005\end{array}$ & $\begin{array}{c}\tan \delta \\
=0.001\end{array}$ & $\begin{array}{c}\tan \delta \\
=0\end{array}$ \\
\hline 8.0 & 0.044 & 0.046 & 0.049 & 0.018 \\
9.0 & 0.051 & 0.054 & 0.057 & 0.036 \\
10.0 & 0.084 & 0.088 & 0.092 & 0.048 \\
11.0 & 0.032 & 0.035 & 0.037 & 0.015 \\
12.0 & 0.016 & 0.018 & 0.020 & 0.008 \\
\hline
\end{tabular}

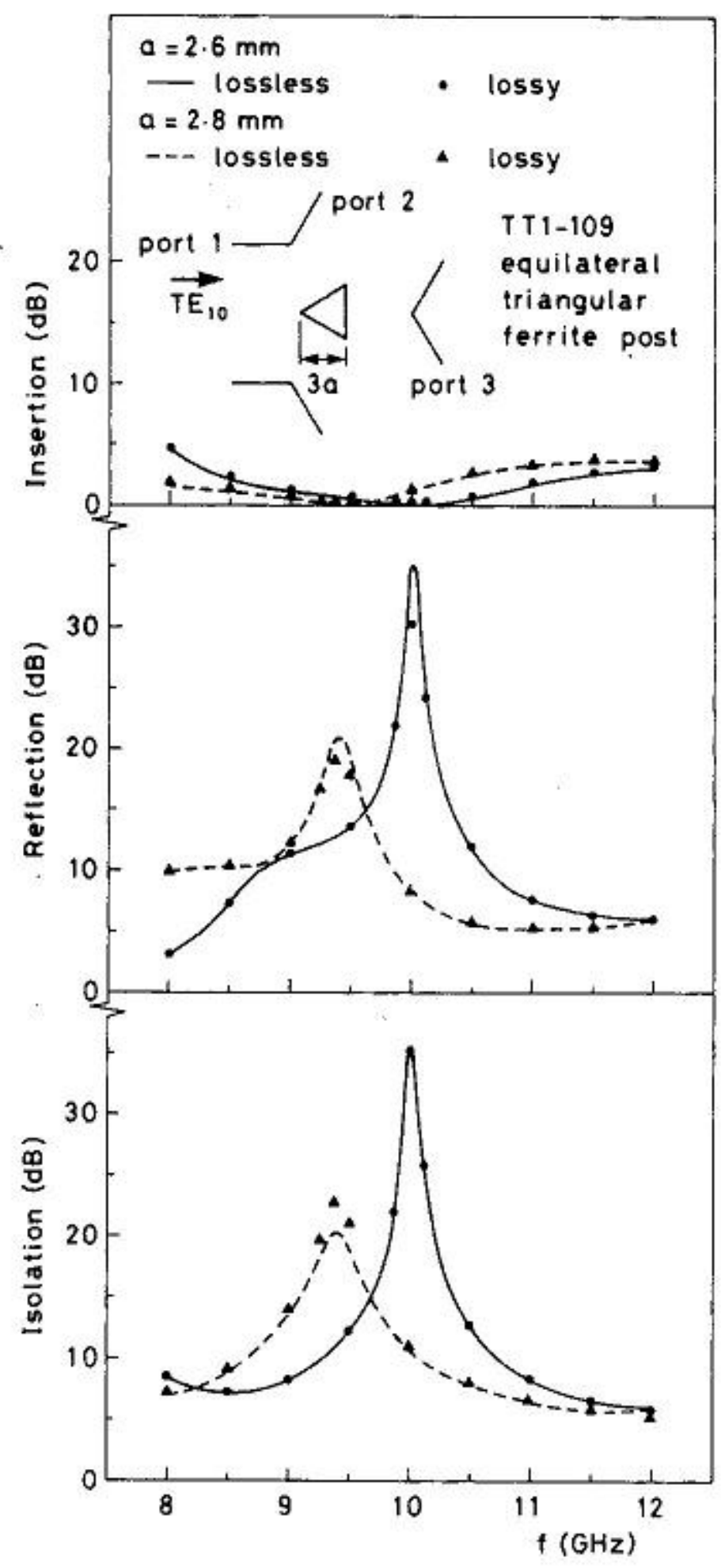

Fig. 5. Performance of a Y-junction with a TT1-109 triangular ferrite post for the first arrangement.

In Fig. 4, the agreement with the experimental results is not as good as in Fig. 3. However, for the lossy cases both in Figs. 3 and 4, the numerical results (dots) agree well with the results of the integral equation method [7]. In comparison with the other theoretical results [3], [5], [6], the integral equation method and the present method are found to give fairly good results close to the experimental results on the whole [7].

Table I shows the dissipative losses. For a TT1-109 ferrite sample, the results obtained by considering both the magnetic and dielectric losses are also shown. It is found

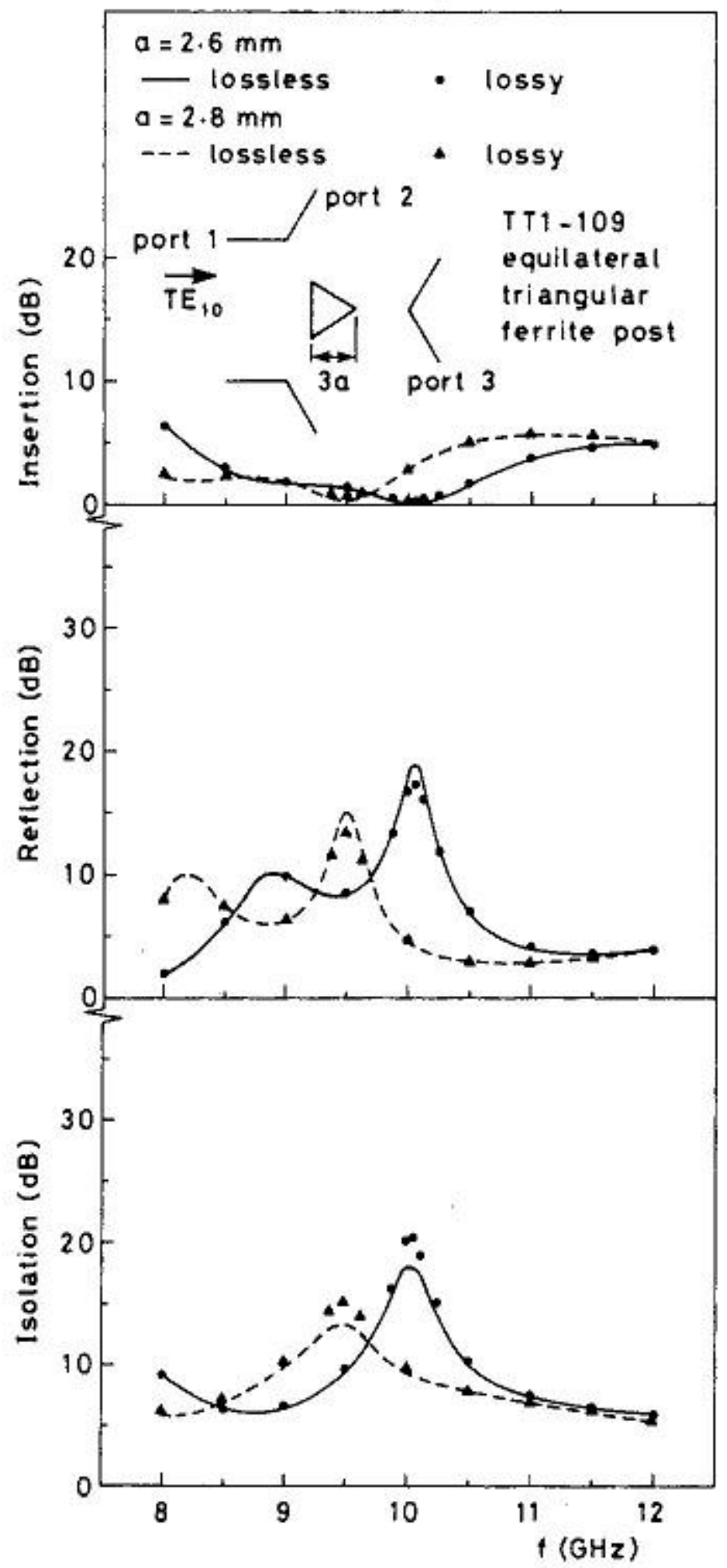

Fig. 6. Performance of a Y-junction with a TT1-109 triangular ferrite post for the second arrangement.

TABLE II

Dissipative LOSSES OF Y-JUNCTIONS WITH A Triangular Ferrite Post

\begin{tabular}{c|c|c|c|c}
\hline \multirow{2}{*}{$\begin{array}{c}\text { Frequency } \\
(\mathrm{GHz})\end{array}$} & \multicolumn{2}{|c|}{$\begin{array}{c}\text { Arrangement } \\
\text { in Fig. } 5\end{array}$} & \multicolumn{2}{c}{$\begin{array}{c}\text { Arrangement } \\
\text { in Fig.6 }\end{array}$} \\
\cline { 2 - 5 } & $a=2.6 \mathrm{~mm}$ & $a=2.8 \mathrm{~mm}$ & $a=2.6 \mathrm{~mm}$ & $a=2.8 \mathrm{~mm}$ \\
\hline 8.0 & 0.032 & 0.051 & 0.029 & 0.055 \\
9.0 & 0.047 & 0.062 & 0.048 & 0.062 \\
9.5 & 0.053 & 0.070 & 0.055 & 0.093 \\
10.0 & 0.059 & 0.053 & 0.074 & 0.053 \\
10.5 & 0.050 & 0.036 & 0.051 & 0.027 \\
11.0 & 0.035 & 0.027 & 0.027 & 0.019 \\
12.0 & 0.021 & 0.021 & 0.015 & 0.017 \\
\hline
\end{tabular}

that dielectric losses do not add much to the dissipative losses. Therefore, we neglect the dielectric losses in the following numerical results.

\section{B. Y-Junction with a Triangular Ferrite Post}

Consider a $\mathrm{Y}$-junction with a triangular equilateral ferrite post. Two specific cases [6] are considered. In the first case, the points of the triangle are in the centers of the waveguides, whereas in the second case, the sides of the triangle are in the centers of the waveguides. Numerical 


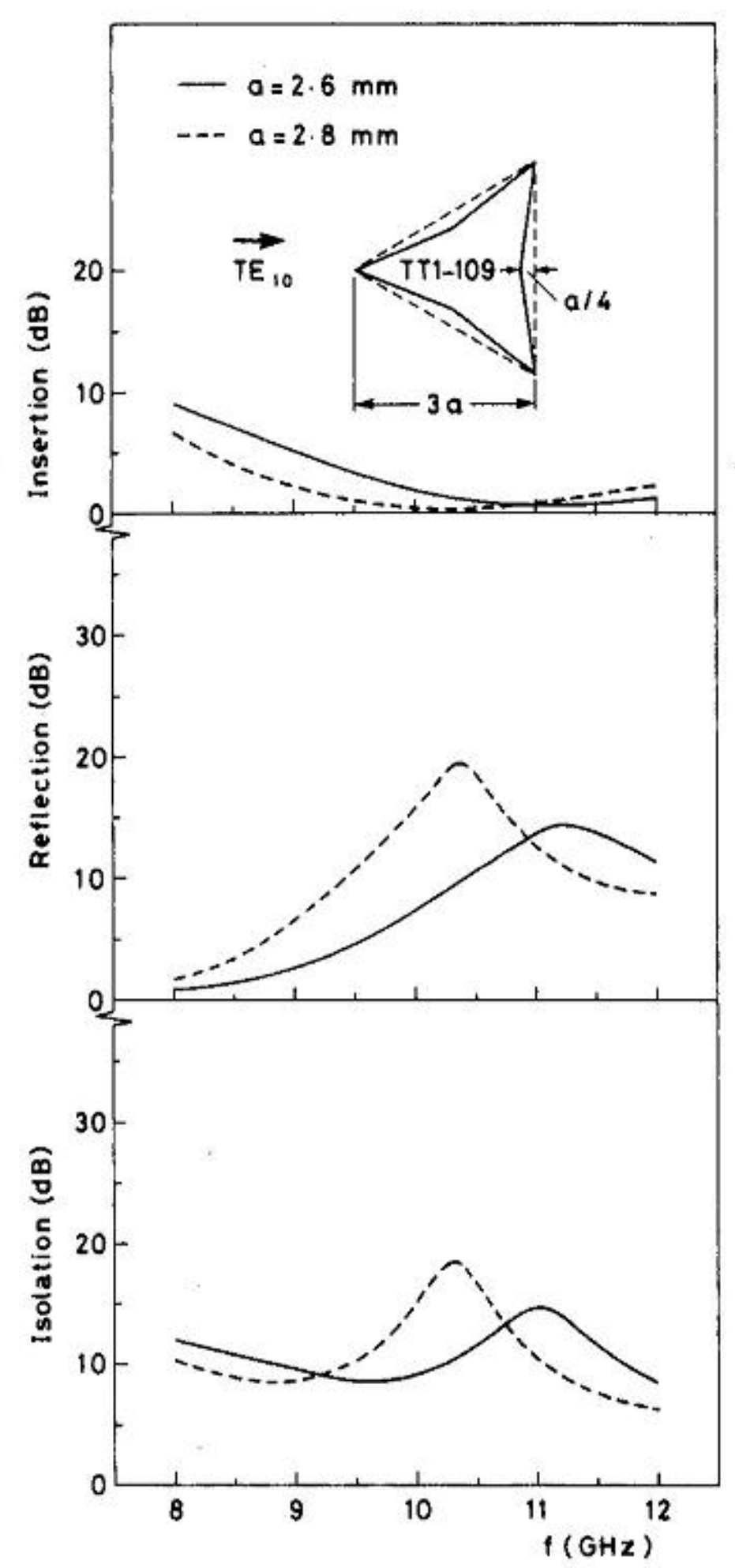

Fig. 7. Performance of a Y-junction with a TT1-109 triangular ferrite post having depressed sides for the first arrangement.

results are obtained for a TT1-109 ferrite sample. The circulator performances for the first and the second arrangements are shown in Figs. 5 and 6, respectively, where $a$ is the radius of an inscribed circle of the triangle. It is found that as the value of $a$ increases, the circulation frequency decreases. In the lossy cases, the isolation slightly meliorates and the reflection slightly deteriorates in the neighborhood of the respective maxima of the performance curves in comparison with the lossless cases. The values of the maximum isolation for the first arrangement (Fig. 5) are larger than those for the second arrangement (Fig. 6).

Table II shows the dissipative losses due to the magnetic losses. The dissipative losses for the first arrangement are smaller than those for the second arrangement in the neighborhood of the circulation frequency.

\section{C. $Y$-Junction with a Triangular Ferrite Post Having Depressed Sides}

We propose a Y-junction with a triangular ferrite post having depressed sides as shown in Figs. 7 and 8. Two specific cases are considered. In the first case (Fig. 7), the points of the triangle are in the centers of the waveguides, whereas in the second case (Fig. 8), the sides of the triangle are in the centers of the waveguides. Numerical results are obtained for a TT1-109 ferrite sample. The circulator performances for the first and the second arrangements are

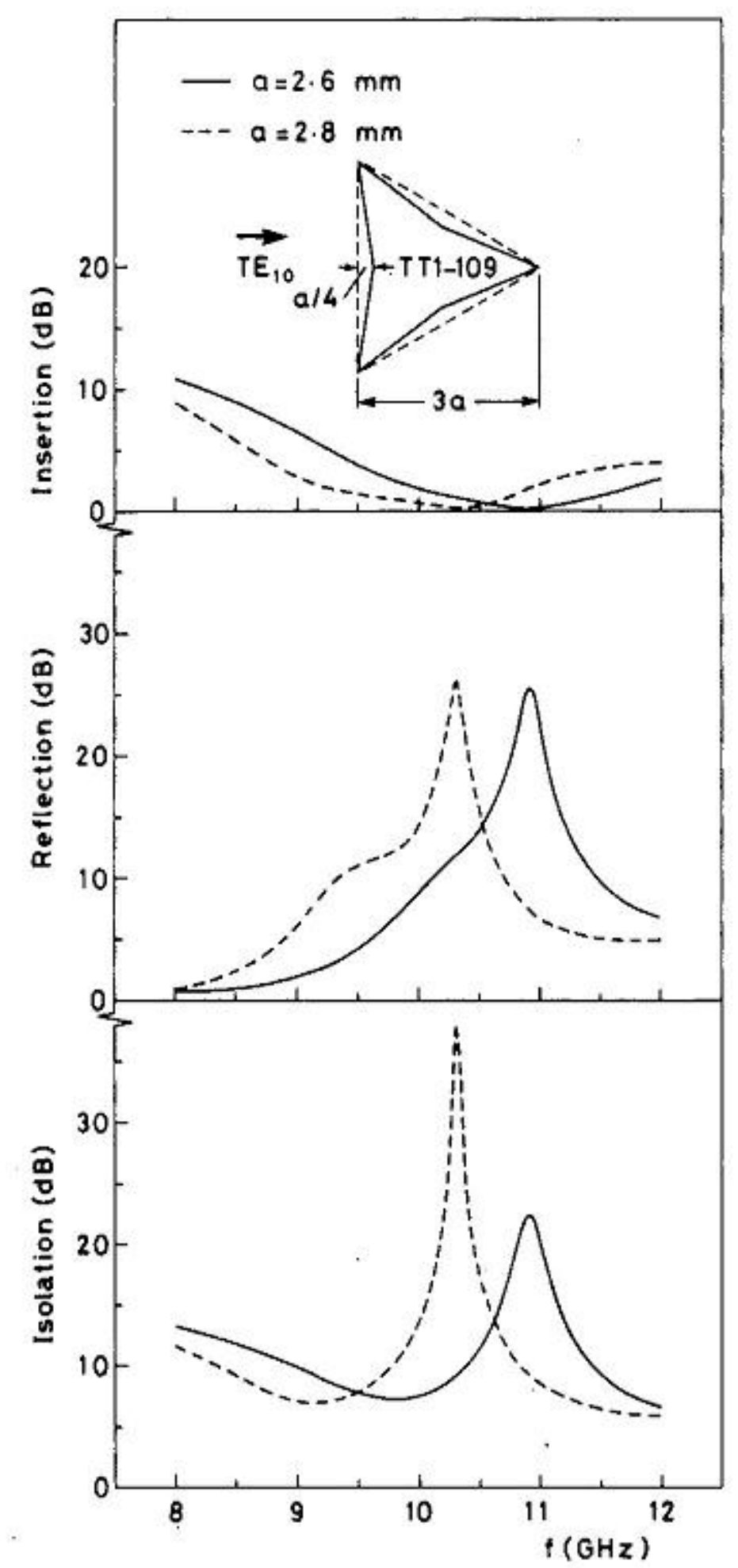

Fig. 8. Performance of a Y-junction with a TT1-109 triangular ferr post having depressed sides for the second arrangement.

shown in Figs. 7 and 8, respectively, where the magnet losses are considered. The frequency of the best isolation for the triangular ferrite post having depressed sides Figs. 7 and 8 is higher than that for the triangular ferrite post in Figs. 5 and 6 . The values of the maximum isolation for the first arrangement (Fig. 7) are smaller than those for the second arrangement (Fig. 8).

In the first arrangement (Fig. 7), the points of triangle, which are in the centers of the waveguides, $m$ act as dielectric tapers [13]. However, each side of triangle is bent abruptly. Therefore, it seems that performances obtained with the triangular ferrite post ha ing depressed sides (Fig. 7) are inferior to those obtaine with the triangular ferrite post having straight sides ( $\mathrm{F}_{1}$ 5). In the second arrangement (Fig. 8), the sides of t triangle, which are in the centers of the waveguides, trimmed [14] and the dissipative losses due to the magne losses may be reduced. Therefore, it seems that the $p$ formances obtained with the triangular ferrite post havi depressed sides (Fig. 8) are better than those obtained w the triangular ferrite post having straight sides (Fig. 6).

Table III shows the dissipative losses due to the ma netic losses. The dissipative losses obtained with the tria gular ferrite post having depressed sides in Table III smaller than those obtained with the triangular ferrite $\mathrm{p}$ in Table II for the same value of $a$. 
TABLE III

DisSIPATIVE LOSSES OF Y-JUNCTIONS WITH A Triangular Ferrite Post HaVing Depressed Sides

\begin{tabular}{c|c|c|c|c}
\hline \multirow{2}{*}{$\begin{array}{c}\text { Frequency } \\
(\mathrm{GHz})\end{array}$} & \multicolumn{2}{|c|}{$\begin{array}{c}\text { Arrangement } \\
\text { in Fig. }\end{array}$} & \multicolumn{2}{c}{$\begin{array}{c}\text { Arrangement } \\
\text { in Fig. } 8\end{array}$} \\
\cline { 2 - 5 } & $a=2.6 \mathrm{~mm}$ & $a=2.8 \mathrm{~mm}$ & $a=2.6 \mathrm{~mm}$ & $a=2.8 \mathrm{~mm}$ \\
\hline 8.0 & 0.013 & 0.021 & 0.014 & 0.017 \\
9.0 & 0.023 & 0.036 & 0.022 & 0.038 \\
9.5 & 0.029 & 0.041 & 0.031 & 0.044 \\
10.0 & 0.034 & 0.044 & 0.038 & 0.052 \\
10.31 & & 0.045 & & 0.057 \\
10.5 & 0.037 & 0.044 & 0.043 & 0.054 \\
10.94 & 0.037 & & 0.045 & \\
11.0 & 0.037 & 0.036 & 0.044 & 0.032 \\
12.0 & 0.026 & 0.022 & 0.019 & 0.015 \\
\hline
\end{tabular}

From Figs. 5-8 and Tables II and III, it is found that it is possible to optimize the form of the cross section of the ferrite to find the best possible circulator structure, namely higher isolation and reflection losses, smaller insertion loss, and smaller dissipative loss at the circulation frequency.

\section{CONCLUSION}

A method of analysis, based on the finite-element approach and the analytical approach, was developed for the solution of $H$-plane waveguide junctions with lossy ferrite posts of arbitrary shape. The validity of the method was confirmed by comparing numerical results for circular ferrite post circulators with previously published experimental and theoretical results. The performances of $\mathrm{Y}$-junction circulators with a triangular equilateral ferrite post or a triangular ferrite post having depressed sides were also investigated. The influences of the ferrite losses on the performance were examined.

This method can be easily extended to the planar circulators using arbitrarily shaped resonators [8]. The problem of how to deal with waveguide junctions with partial-height ferrite posts [15]-[17] hereafter still remains.

\section{ACKNOWLEDGMENT}

The authors wish to thank M. Sato for his assistance in numerical computations.

\section{REFERENCES}

[1] J. B. Davies, "An analysis of the $m$-port symmetrical $H$-plane waveguide junction with central ferrite post," IRE Trans. Microwave Theory Tech., vol. MTT-10, pp. 596-604, Nov. 1962

[2] C. G. Parsonson, S. R. Longley, and J. B. Davies, "The theoretical design of broad-band 3-port waveguide circulators," IEEE Trans. Microwave Theory Tech., vol. MTT-16, pp. 256-258, Apr. 1968.

[3] J. B. Castillo, Jr., and L. E. Davis, "Computer-aided design of three-port waveguide junction circulators," IEEE Trans. Microwave Theory Tech., vol. MTT-18, pp. 25-34, Jan. 1970.

[4] J. B. Castillo and L. E. Davis, "A higher order approximation for waveguide circulators," IEEE Trans. Microwave Theory Tech., vol. MTT-20, pp. 410-412, June 1972.

[5] M. E. El-Shandwily, A. A. Kamal, and E. A. F. Abdallah, "General field theory treatment of $H$-plane waveguide junction circulators," IEEE Trans. Microwave Theory Tech., vol. MTT-21, pp. 392-408, June 1973.

[6] A. Khilla and I. Wolff, "Field theory treatment of $H$-plane waveguide junction with triangular ferrite post," IEEE Trans. Microwave Theory Tech., vol. MTT-26, pp. 279-287, Apr. 1978.
[7] N. Okamoto, "Computer-aided design of $H$-plane waveguide junctions with full-height ferrites of arbitrary shape," IEEE Trans. Microwave Theory Tech., vol. MTT-27, pp. 315-321, Apr. 1979.

[8] R. W. Lyon and J. Helszajn, "A finite element analysis of planar circulators using arbitrarily shaped resonators," IEEE Trans. Microwave Theory Tech., vol. MTT-30, pp. 1964-1974, Nov. 1982.

[9] B. Lax and K. J. Button, Microwave Ferrites and Ferrimagnetics. New York: McGraw-Hill, 1962.

[10] M. Suzuki and M. Koshiba, "Finite element analysis of discontinuity problems in a planar dielectric waveguide," Radio Sci., vol. 17, pp. 85-91, Jan.-Feb. 1982

[11] M. Koshiba, M. Sato, and M. Suzuki, "Application of finite-element method to $H$-plane waveguide discontinuities," Electron. Lett., vol. 18, pp. 364-365, Apr. 1982.

[12] M. Koshiba, M. Sato, and M. Suzuki, "Finite-element analysis of arbitrarily shaped $H$-plane waveguide discontinuities," Trans. Inst. Electron. Commun. Eng. Japan, vol. E66, pp. 82-87, Feb. 1983.

[13] C. E. Fay and R. L. Comstock, "Operation of the ferrite junction circulator," IEEE Trans. Microwave Theory Tech., vol. MTT-13, pp. 15-27, Jan. 1965.

[14] N. Ogasawara and T. Noguchi, "Modal analysis of the dielectric stub of the normal triangular cross-section," Inst. Electron. Commun. Eng. Japan, Tech. Res. Rep. MW74-22, June 1974 (in Japanese).

[15] Y. Akaiwa, "Operation modes of a waveguide Y circulator," IEEE Trans. Microwave Theory Tech., vol. MTT-22, pp. 954-960, Nov. 1974.

[16] J. Helszajn and F. C. Tan, "Design data for radial-waveguide circulators using partial-height ferrite resonators," IEEE Trans. Microwave Theory Tech., vol. MTT-23, pp. 288-298, Mar. 1975.

[17] Y. Akaiwa, "A numerical analysis of waveguide $H$-plane Y-junction circulators with circular partial height ferrite post," Trans. Inst. Electron. Commun. Eng. Japan, vol. E61, pp. 609-617, Aug. 1978.

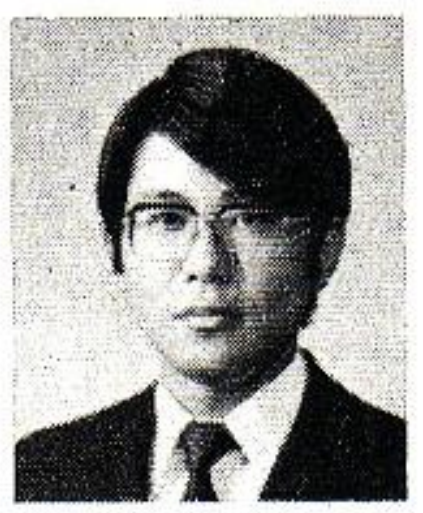

Masanori Koshiba (SM'84) was born in Sapporo, Japan, on November 23, 1948. He received the B.S., M.S., and Ph.D. degrees in electronic engineering from Hokkaido University, Sapporo, Japan, in 1971, 1973, and 1976, respectively.

In 1976, he joined the Department of Electronic Engineering, Kitami Institute of Technology, Kitami, Japan. Since 1979, he has been an Assistant Professor of Electronic Engineering at Hokkaido University. $\mathrm{He}$ has been engaged in research on surface acoustic waves, dielectric optical waveguides, and applications of finite-element and boundary-element methods to field problems.

Dr. Koshiba is a member of the Institute of Electronics and Communication Engineers of Japan, the Institute of Television Engineers of Japan, the Institute of Electrical Engineers of Japan, the Japan Society for Simulation Technology, and the Japan Society for Computational Methods in Engineering.

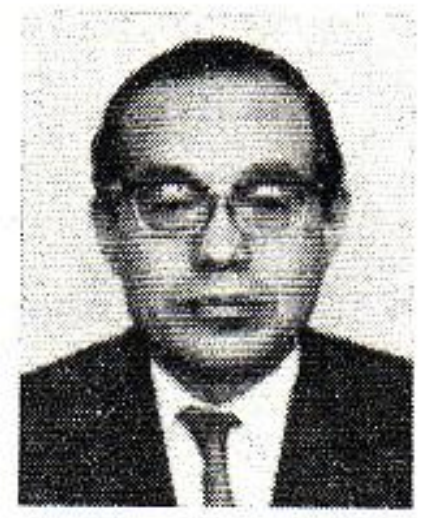

Michio Suzuki (SM'57) was born in Sapporo, Japan, on November 14, 1923. He received the B.S. and Ph.D. degrees in electrical engineering from Hokkaido University, Sapporo, Japan, in 1946 and 1960, respectively.

From 1948 to 1962, he was an Assistant Professor of Electrical Engineering at Hokkaido University, Since 1962, he has been a Professor of Electronic Engineering at Hokkaido University. From 1956 to 1957 , he was a Research Associate at the Microwave Research Institute of Polytechnic Institute of Brooklyn, Brooklyn, NY.

Dr. Suzuki is a member of the Institute of Electronics and Communication Engineers of Japan, the Institute of Electrical Engineers of Japan, the Institute of Television Engineers of Japan, the Japan Society of Information and Communication Research, and the Japan Society for Simulation Technology. 